\title{
Biosynthesis of cellulose microfibre from peanut shell for the preparation of bio-nanocomposite films for food-packaging application
}

\author{
L F A ANAND RAJ*D, R SHANMUGAPRIYA and J JESLIN \\ Department of Biotechnology, St. Joseph's College of Engineering, Chennai 600 119, India \\ *Author for correspondence (anandlfa@yahoo.co.in)
}

MS received 2 March 2018; accepted 25 August 2018; published online 6 March 2019

\begin{abstract}
Synthetic petroleum-based products are normally used for food-packaging application which results in environmental pollution. This creates a need to develop biodegradable polymer and polymer-based films to maintain the stability of packed materials for a defined period of time that will overcome the drawbacks of the synthetic petroleumbased packaging system. The current work is focussed on evaluating the potential of cellulose agar bio-nanocomposite films in food packaging application. The physical and mechanical properties such as its tensile strength (TS), Young's modulus (YM) and elongation at break $(E)$ were found to be increased on loading with cellulose microfibre (CMF). TS is found to be increased from $38.8 \pm 3.2$ to $49.4 \pm 4.3$ and there is about $6 \%$ increase in the elongation at break. Similarly, CMF films exhibit $54 \pm 0.2 \%$ water solubility, 1.304 opacity and $1.71 \pm 0.07 \mathrm{GPa}$, respectively. Also, the bionanocomposite film showed less swelling property and an increase in soil degradation rate, enabling it to be applied in food packaging.
\end{abstract}

Keywords. Synthetic; biodegradable; bio-nanocomposite; food packaging.

\section{Introduction}

In recent years, many efforts have been made by researchers all over the world to convert petroleum-based synthetic products into an eco-friendly material, especially in food industries [1]. Synthetic polymers from fossil fuels create a wide environmental problem due to their non-renewable and non-biodegradable nature [2]. Biopolymer and its biodegradability nature has made researchers to pay attention towards its production and its major advantages are the decrease in environmental pollution, increasing shelf-life of the product, increasing the nutrient value of food, preserving its quality and preventing microbial contamination $[3,4]$. Several other features including low cost, easy availability, functional attributes, good mechanical and physical properties, opacity and resistance to water concludes that biopolymers can be used as a versatile material for food packaging applications [5]. Recent trends have been focussed on the preparation of biopolymer-based food-packaging materials produced from proteins, carbohydrates and lipids.

Among various biopolymers, cellulose is abundantly available fibrillated linear polysaccharide, composed of $\beta$-Dglucopyranosyl residues with a network of interlocked fibres with a high crystallinity and a high degree of polymerization [6,7]. It consists of 100 glucon chains that are grouped together to form a long thin crystallite, longer than microfibrils in micron length [8]. Currently, 3.2 million tonnes of cellulose are being used every year for the synthesis of various cellulosic material, such as optical films, coating agents and laminates [9]. The major source of cellulose is lignocellulosic materials which include wood, plants, stalks, nuts, husk, shells, straw, root, leaves, etc. Lignocellulosic biomass is composed of semi-crystalline cellulose, with amorphous hemicellulose, lignin and a minute quantity of other extracts [10-13]. Because of its biodegradability, bioavailability and thermostability, it can be used as an alternative to petroleumand synthetic-based products $[7,11]$.

The food packaging films produced using cellulose would be clear, transparent, strong and flexible. The application of this cellulose in the packing of food products has increased due to its good mechanical properties and hydrophilic characteristics [1,14].

The current work aims to overcome the use of petroleumbased products by cellulose-agar bio-nanocomposite film. Agar is one among the natural polymers, unbranched polysaccharide and it has a good tensile strength (TS), polymerizing ability, low density and good thermal stability $[15,16]$. Owing to the reinforcement of cellulose binding with agarpolymer matrix, bio-nanocomposite films were produced which exhibit improved physical, mechanical and thermal properties and there can be deployed for food-packaging applications. 


\section{Experimental}

\subsection{Materials}

Peanut shells and fresh papaya leaves were collected from the local market (Chennai). Chemicals such as $\beta$ mercaptoethanol, polyvinylpyrrolidone, sodium chlorite, potassium hydroxide, acetic acid and sodium acetate in analytical grade were purchased from Fisher Scientific (India).

\subsection{Production of laccase from Carica papaya leaves}

2.2a Extraction of laccase enzyme: Twenty grams of fresh leaves of papaya were homogenized using ice-cold Tris- $\mathrm{HCl}$ buffer (100 mM). Polyvinylpyrrolidone and $\beta$ mercaptoethanol were added during extraction. The homogeneous slurry was centrifuged at $8000 \mathrm{rpm}$ for $30 \mathrm{~min}$ in a cooling centrifuge. The supernatant was collected and it was further purified by the heat treatment. The extract was heated at $70^{\circ} \mathrm{C}$ for $40 \mathrm{~min}$ and was immediately cooled. The content was then centrifuged at $8000 \mathrm{rpm}$ for $20 \mathrm{~min}$. The final supernatant was collected which contained $80 \%$ pure laccase enzyme [17].

2.2b Enzyme assay activity: The enzyme activity of laccase was determined by the 2,2'-azino-bis(3ethylbenzothiazoline-6-sulphonic acid) (ABTS) method [18]. The assay mixture contains $1.5 \mathrm{ml}$ of $0.5 \mathrm{mM}$ ABTS, $1.5 \mathrm{ml}$ sodium acetate buffer ( $1 \mathrm{mM}, \mathrm{pH}$ ) and $1 \mathrm{ml}$ of crude enzyme and the reaction was monitored by measuring the change in the absorbance at $436 \mathrm{~nm}$ after $3 \mathrm{~min}$. The blank consists of no enzyme [19]. Using bovine serum albumin as the standard, protein concentration was estimated by Bradford's method.

\subsection{Isolation of cellulose microfibre from peanut shell}

Three stages of treatments were involved in the isolation process, namely, enzymatic pretreatment, chemical treatment and ultrasonic treatment. At first, peanut shells were washed, dried at $105^{\circ} \mathrm{C}$ for $24 \mathrm{~h}$ and grounded into powder. This peanut shell powder (PSP) was stored in a refrigerator for further studies. Sodium acetate buffer was added to the PSP and maintained at pH 5 using $10 \%$ acetic acid. Hundred milligrams of crude laccase extract was added to the suspension and kept for $24 \mathrm{~h}$ at $160 \mathrm{rpm}$ at $60^{\circ} \mathrm{C}$ in the orbital shaker. The enzyme was added to initiate partial lignin oxidation and to involve in the limited removal of lignin from the shell. After $24 \mathrm{~h}$, the fibre suspension was filtered and washed with distilled water. It was then dried by exposing to heat at $90^{\circ} \mathrm{C}$ for $24 \mathrm{~h}$ to stop the enzymatic reaction. The dried fibres were then purified by chemical treatments. Initially, fibres were bleached using sodium chlorite $(0.8 \%, \mathrm{w} / \mathrm{v})$ at $75^{\circ} \mathrm{C}$ for $1 \mathrm{~h}$. Then, it was subjected to alkaline treatment with $3 \%$ potassium hydroxide (w/v) at $90^{\circ} \mathrm{C}$ for $3 \mathrm{~h}$. Further, it was treated with $6 \%$ potassium hydroxide (w/v) at $85^{\circ} \mathrm{C}$ for another $4 \mathrm{~h}$ to remove the remaining lignin, hemicellulose and ash. Finally, the suspension was neutralized by filtering and washing with distilled water several times. The samples were kept in the wet suspended state throughout the process to avoid bonding of fibres as the fibre matrix was removed [20].

\subsection{Preparation of bio-nanocomposite films}

The agar and agar-based nanocomposite was produced through a solution casting method. Four grams of agar powder was dissolved in $100 \mathrm{ml}$ of distilled water along with 4 $\mathrm{ml}$ of glycerol as a plasticizer. Then it was mixed vigorously using a magnetic stirrer at $90^{\circ} \mathrm{C}$ for $30 \mathrm{~min}$. Subsequently it was cast into the Petri plate and dried at $50^{\circ} \mathrm{C}$ for $24 \mathrm{~h}$ [21]. To prepare PSP and CMF bio-nanocomposite films, $0.5 \mathrm{~g}$ of PSP and $\mathrm{CMF}$ and $4 \mathrm{~g}$ of agar were dissolved in $100 \mathrm{ml}$ distilled water and mixed vigorously for $1 \mathrm{~h}$ at room temperature. This wet suspension was homogenized using an ultrasonic homogenizer for $10 \mathrm{~min}$ in an ice-cold bath. Four grams of agar and $4 \mathrm{ml}$ of glycerol were added to the fibre suspension and were stirred for $1 \mathrm{~h}$ at $90^{\circ} \mathrm{C}$. Further, this suspension was cast onto the Petri plate and dried for $24 \mathrm{~h}$. After $24 \mathrm{~h}$, dried films were peeled off from the plate and stored in the humidity chamber to maintain constant humidity for further analysis $[1,7]$.

\subsection{Characterization of $C M F$}

The morphological structure of CMF was visualized through a field emission scanning electron microscope (FESEMSUPRA 55, Carl Zeiss, Germany). Fourier transform infrared (FTIR) spectra of PSP and CMF were recorded using an FTIR (ATR-IR) spectrophotometer (Perkin Elmer spectrum with resolution of $1.0 \mathrm{~cm}^{-1}$ ) in the range of $450-4000 \mathrm{~cm}^{-1}$. X-ray diffraction (XRD) pattern of PSP and CMF were analysed using an X-ray diffractometer (XRD-SMART, Rigaku, Japan). The powdered samples were analysed over the range of diffraction angles of $2 \theta=5-50^{\circ}$ with the scanning rate of $0.4^{\circ} \mathrm{min}^{-1}$. Crystallinity index $(\mathrm{CrI})$ of the samples was calculated based on Segal's empirical method using the following equation [22]:

$$
\mathrm{CrI}=\frac{I_{200}-I_{\text {Amorph }}}{I_{200}} \times 100,
$$

where $\mathrm{CrI}$ is the degree of crystallinity, $I_{200}$ the maximum intensity $\left(2 \theta=22^{\circ}\right)$ and $I_{\text {Amorph }}$ the intensity diffraction between 22 and $16^{\circ}$, which was located at around $2 \theta=18^{\circ}$. Using the Scherrer equation, the crystallite size $(D)$ was calculated as below:

$$
D=\frac{K \lambda}{\beta^{1 / 2} \cos \theta},
$$

where $K$ is the Scherrer constant (0.94), $\lambda$ the X-ray wavelength $(\lambda=1.54056), \beta^{1 / 2}$ is the full width at half maximum and $\theta$ the Bragg's angle [23]. 


\subsection{Characterization of bio-nanocomposite films}

2.6a Film thickness: Thickness of the films was measured using a manual micrometer at 10 different positions with the error of $0.001 \mathrm{~mm}$. The mean values were calculated as film thickness and used for measuring TS and opacity of the films.

2.6b Mechanical properties of the films: Mechanical properties of the prepared films such as TS, Young's modulus $(Y M)$ and elongation at break $(E)$ were calculated by Universal testing machine and ASTM standard method was followed (ASTM D882-02). The test was carried out in five film samples.

2.6c Water solubility: To measure the solubility of the films in water, initially, the films were dried at $100^{\circ} \mathrm{C}$ for $24 \mathrm{~h}$ and weighed $\left(W_{1}\right)$. Further, the films were dipped into $100 \mathrm{ml}$ distilled water at room temperature for $24 \mathrm{~h}$. Then, the films were separated and dried at $100^{\circ} \mathrm{C}$ for $24 \mathrm{~h}\left(W_{2}\right)$ [24]. The water solubility\% was calculated using the below equation:

$$
\mathrm{WS} \%=\frac{W_{1}-W_{2}}{W_{1}} \times 100 .
$$

2.6d Light transmission and opacity: Bionanocomposite films were examined for light transmission property by cutting the film sample into a rectangular shape and were scanned under UV-Vis spectroscopy at a wavelength between 200 and $800 \mathrm{~nm}$ [25]. The opacity of the films was found by taking the absorbance at $600 \mathrm{~nm}$ using a UV-Vis spectrophotometer and was calculated using the following equation:

$$
\text { Opacity }=\frac{A_{600}}{X}
$$

where $X$ is the film thickness ( $\mathrm{mm})$.

2.6e Swelling properties: Swelling properties of the prepared films were initiated by weighing the dry mass of the film sample $\left(W_{\mathrm{d}}\right)$ and they were dropped into the beaker containing $100 \mathrm{ml}$ of distilled water [26]. Weights of the samples were measured at regular time intervals $(15,30,45,60,75$, $90 \mathrm{~min}$ ) and before weighing, the surface water of the samples were absorbed using a filter paper and weighed $\left(W_{\mathrm{w}}\right)$. Swelling properties of the samples were found using the below equation:

$$
\text { Swelling } \%=\frac{W_{\mathrm{w}}-W_{\mathrm{d}}}{W_{\mathrm{d}}} \times 100 .
$$

2.6f Soil burial degradation: Soil burial degradation was carried out by calculating weight loss of the samples buried in the soil environment [27]. Film samples were cut at equal size, weighed and buried in a box containing moist soil.
The soil film with the sample was moisturized daily using distilled water and the samples were taken at a predetermined interval of every 5 days. At every interval, samples were removed and dried to have constant moisture content and weighed. Weight loss of the samples was calculated by:

$$
\text { Weight loss } \%=\frac{W_{\mathrm{o}}-W_{\mathrm{t}}}{W_{\mathrm{o}}} \times 100 \text {, }
$$

where $W_{\mathrm{o}}$ is the initial mass and $W_{\mathrm{t}}$ the remaining mass at a given time.

\section{Results}

\subsection{FESEM}

FESEM is one of the effective method of visualizing the morphological structure of isolated CMF. Figure 1a shows the surface appearance of the isolated CMF from peanut shell after enzymatic and chemical treatments and its size varies in the micrometre range. Naturally, the morphology of peanut shell appears to have a skeletal structure with a smooth surface made up of cellulose wrapped around by lignin and hemicellulose. However, when the peanut shell was subjected to enzymatic and chemical treatments, the surface of peanut shell becomes rough as shown in figure 1a. This is due to the removal of cementing hemicellulose and lignin [1].
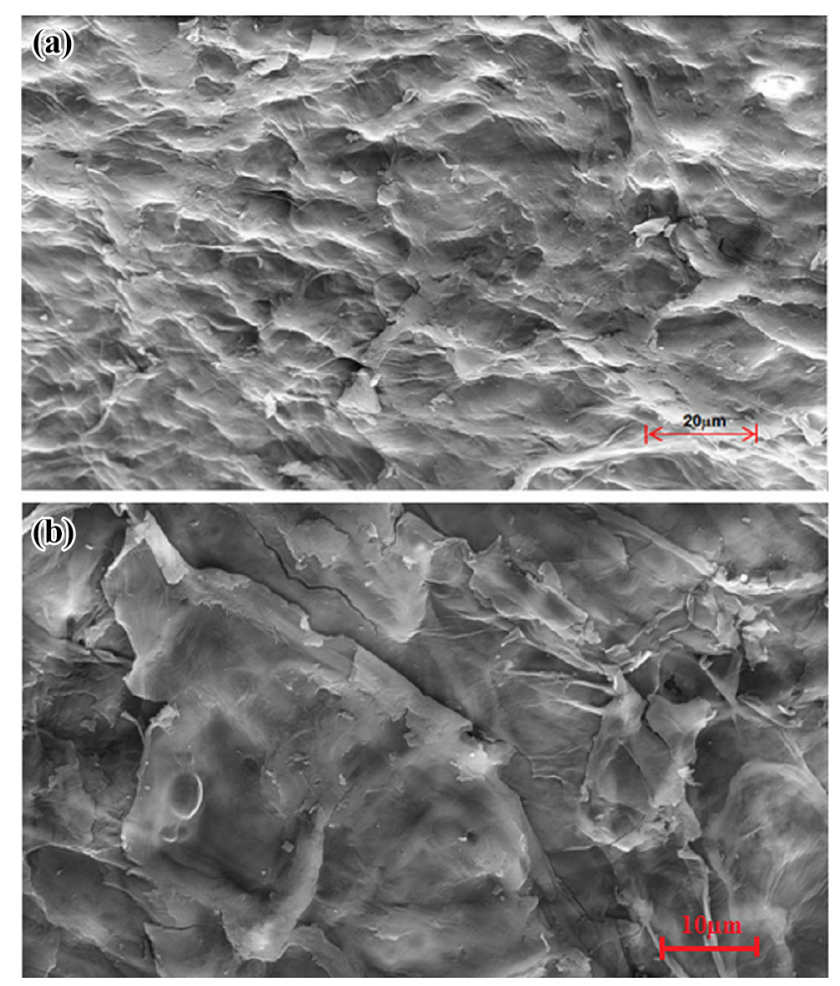

Figure 1. (a and b) FESEM images of rougher surface of CMF. 
(a)

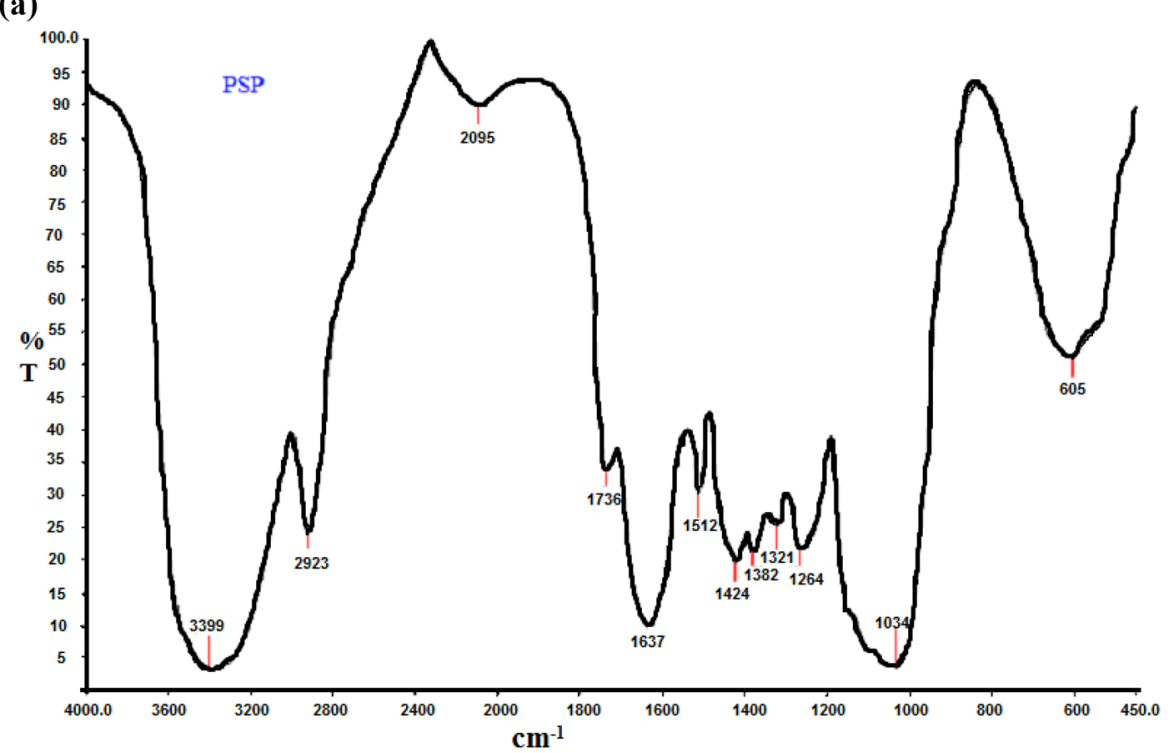

(b)

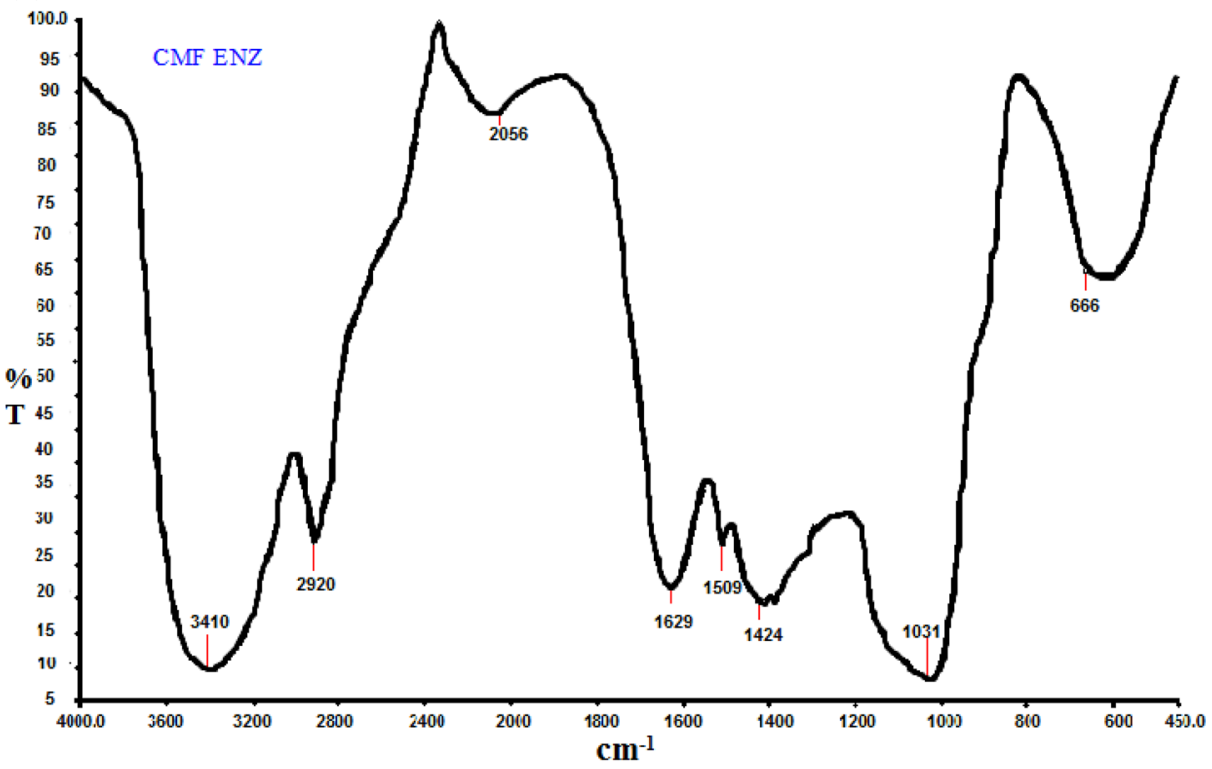

(c)

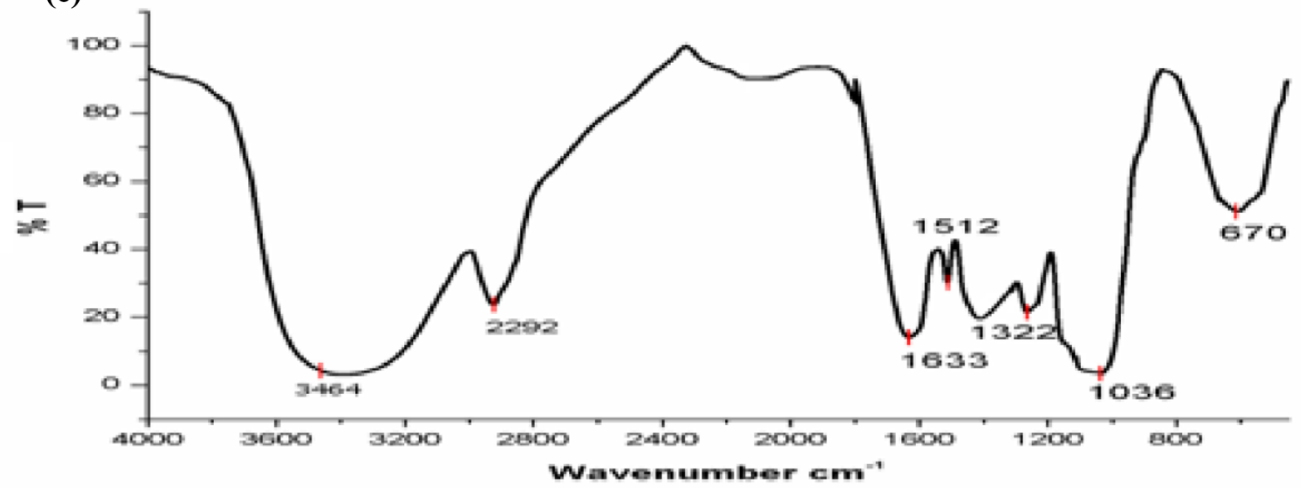

Figure 2. FTIR spectra of (a) PSP, (b) CMF and (c) CMF after chemical treatment. 


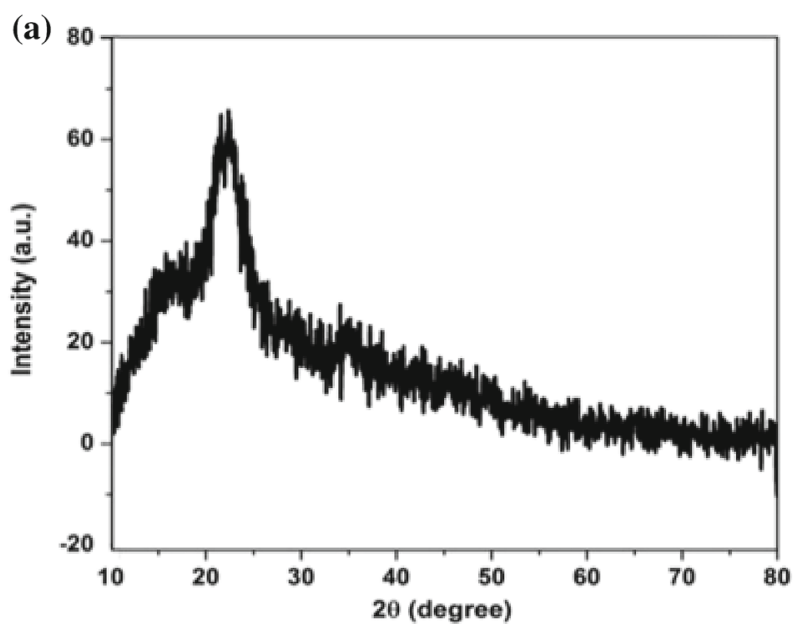

(b)

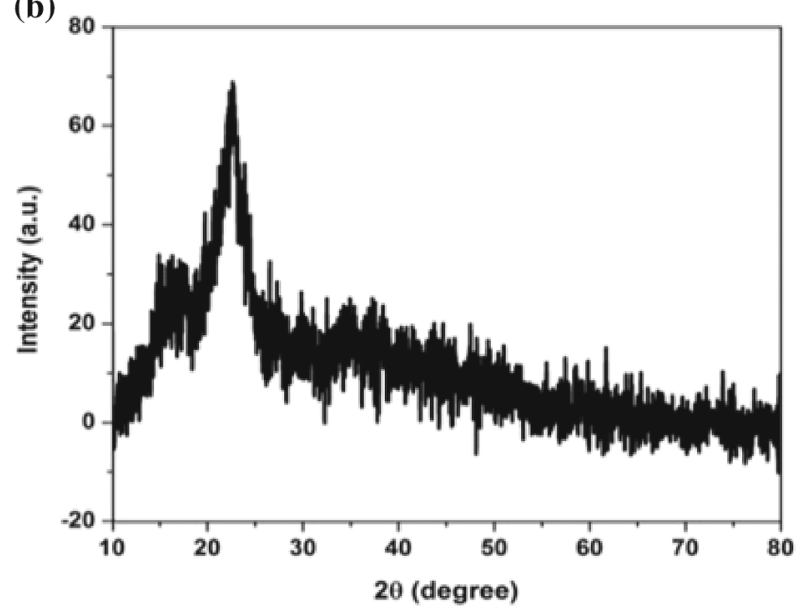

Figure 3. XRD patterns of the natural fibre of (a) PSP and treated CMF.

Table 1. CrI and crystallite size of the samples.

\begin{tabular}{lcc}
\hline Samples & CrI $(\%)$ & Crystallite size $(D)(\mathrm{nm})$ \\
\hline PSP & 64 & 18.8 \\
CMF & 73 & 7.6 \\
\hline
\end{tabular}

In the present study, laccase enzyme from, Carica papaya leaves was used for the partial removal of lignin by oxidizing it and making it soluble. Certain chemicals, such as sodium

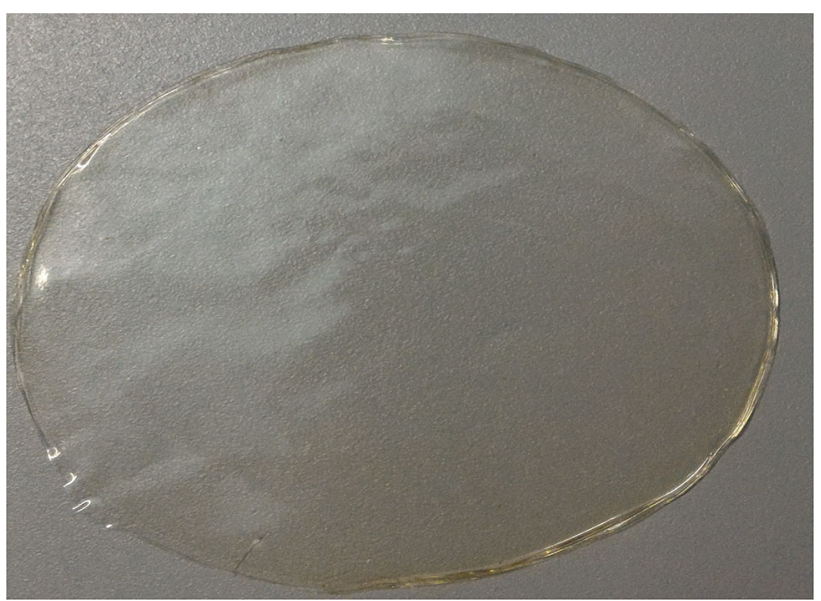

Figure 4. Cellulose agar bio-nanocomposite film.

chlorite and potassium hydroxide were also, applied for the complete removal of lignin and hemicellulose.

\subsection{FTIR analysis}

Figure $2 \mathrm{a}$ and $\mathrm{b}$ shows FTIR spectra of PSP and CMF, respectively. The absorption peak around $3400 \mathrm{~cm}^{-1}$ in PSP and $\mathrm{CMF}$ is due to the stretching vibration of -OH group of cellulose. The intense peak around 2920 and $1030 \mathrm{~cm}^{-1}$ are associated to $\mathrm{C}-\mathrm{H}$ (hydroxyl) stretching vibration and $\mathrm{C}-\mathrm{O}-\mathrm{C}$ structure of D-glucosidic linkage of cellulose, which implies the presence of cellulose in both the spectra [28]. The prominent peaks of PSP at 1736 and $1264 \mathrm{~cm}^{-1}$ are attributed to carbonyl aldehyde $(\mathrm{C}=\mathrm{O})$ and acetyl and uronic ester $(\mathrm{C}-\mathrm{O})$ group and confirm the presence of hemicellulose and lignin [29], respectively. The absence of these peaks in the spectra of CMF confirms the complete removal of lignin and hemicellulose by laccase as shown in figure $2 \mathrm{c}$, followed by the chemical treatment [11]. The peaks at 1424 and $1510 \mathrm{~cm}^{-1}$ correspond to $\mathrm{CH}_{2}$ scissoring and $\mathrm{O}-\mathrm{H}$ bending vibration of cellulose, respectively. Thus, FTIR analysis confirms the presence of cellulose and significant removal of hemicellulose and lignin in CMFs.

\subsection{XRD analysis}

XRD diffractogram profiles of PSP are shown in figure $3 \mathrm{a}$ and those of CMF in figure 3b. A sharp intensive peak of PSP and

Table 2. Physical and mechanical properties of film samples.

\begin{tabular}{lcccccc}
\hline Samples & Thickness (mm) & TS (MPa) & YM (GPa) & $E(\%)$ & Water solubility (WS\%) & Opacity \\
\hline AG film & $0.19 \pm 0.01$ & $38.8 \pm 3.2$ & $1.11 \pm 0.10$ & $26.3 \pm 2.6$ & $71 \pm 0.5$ & 0.515 \\
PSP film & $0.20 \pm 0.04$ & $42.5 \pm 1.6$ & $1.25 \pm 0.09$ & $29.7 \pm 4.4$ & $63 \pm 0.5$ & 0.696 \\
CMF film & $0.23 \pm 0.02$ & $49.4 \pm 4.3$ & $1.71 \pm 0.07$ & $32.0 \pm 5.4$ & $54 \pm 0.2$ & 1.304 \\
\hline
\end{tabular}


(a)

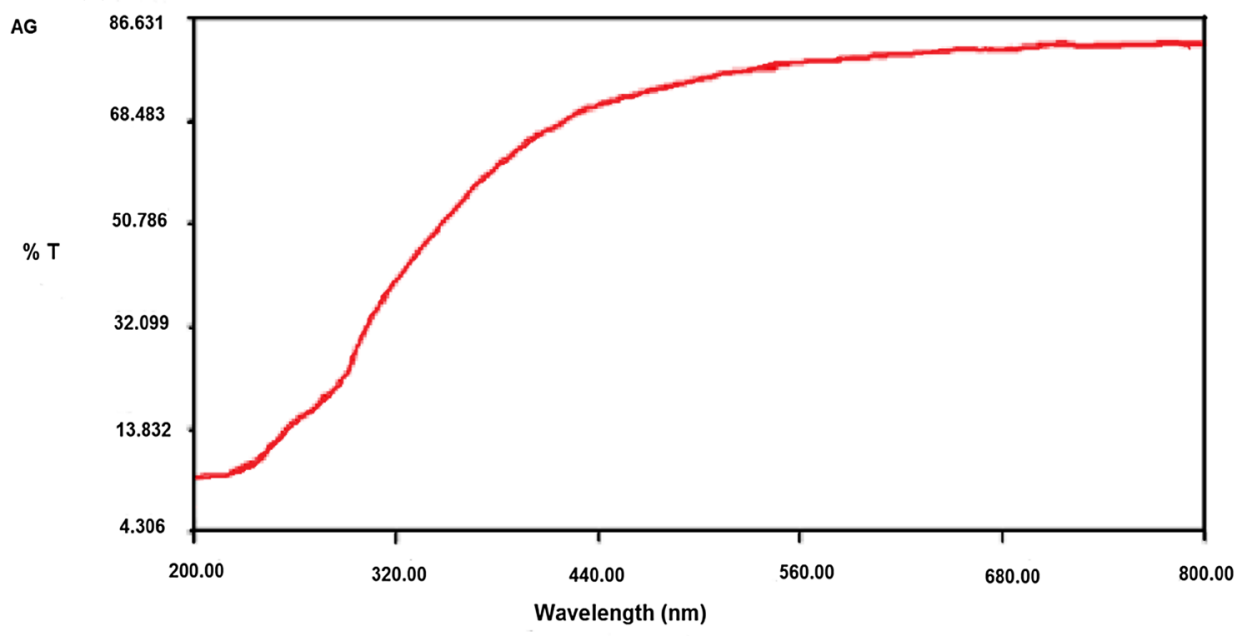

(b)

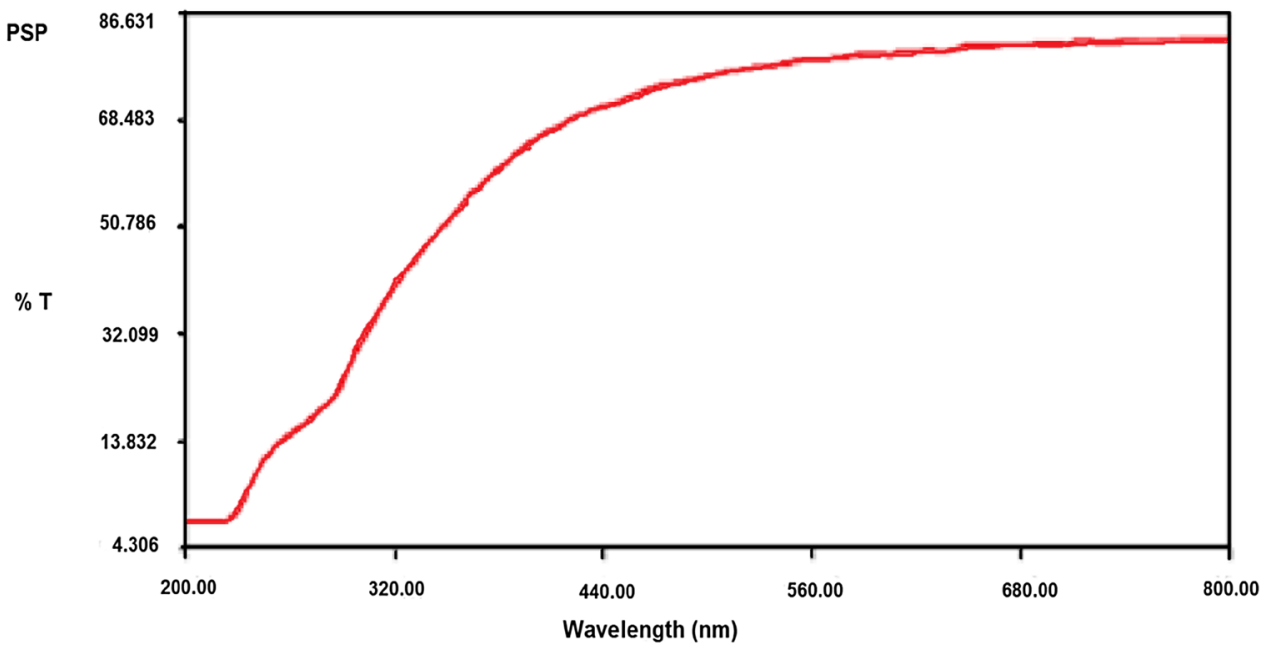

(c)

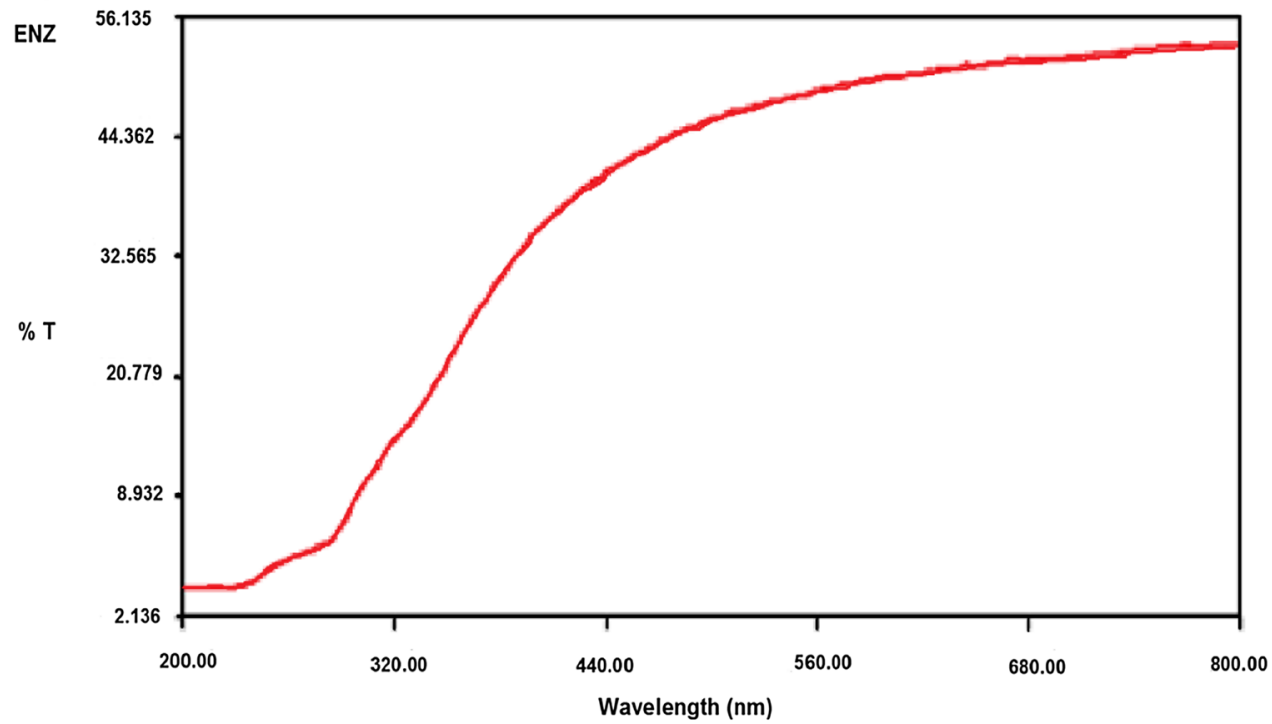

Figure 5. Light transmissions of (a) AG film, (b) PSP film and (c) CMF film. 
CMF was observed around $2 \theta=22.6$ and $22.8^{\circ}$, respectively. The crystal lattice of type-I cellulose was confirmed by these peaks [30]. Segal's empirical method was used to calculate the CrI [31] which can be used to compare the relative amount of crystalline material present in the natural PSP and treated CMF. The CrI of untreated PSP was found to be $64 \%$ and that of CMF was $73 \%$. From the XRD profiles, it can be observed that the decrement of CrI in the untreated PSP was due to the presence of larger portion of lignin and hemicellulose and the increase in crystallinity of CMF was due to the enzymatic and chemical treatments that help in the dissolution of amorphous hemicellulose and lignin [32]. Table 1 presents $\mathrm{CrI}$ and crystallite size $(D)$ of the samples. In contrast to the CrI, the crystallite size of PSP is decreased by the process of enzymatic and chemical treatments. This reduction in the size of fibres was because of certain treatments which cause breakage of cellulose fibres and converting them from bundles to an individual fibre [33].

\subsection{Characterization of bio-nanocomposite films}

3.4a Physical and mechanical properties: These properties of agar and agar-based nanocomposite films were measured and are shown in table 2. From the result, it is observed that TS of AG film was lower than that of the other two films. TS increases for the CMF film, which is due to the formation of strong interfacial adhesiveness between the cellulose and the polymer matrix. On loading the cellulose, the TS of the film increases from $38.8 \pm 3.2$ to $49.4 \pm 4.3$ which is due to the formation of a strong $\mathrm{H}$-bond between agar and cellulose fibre $[34,35]$. On chemical treatment, fibre gets defibrillated on the surface and increases surface roughness and hence, the fibre matrix helps to form strong composite films. YM indicates the stiffness of the films and the results are tabulated in table 1. From the results, YM seems to be similar to that of TS of the composite films and it shows that CMF films exhibit high mechanical strength when compared with other films. The elongation at break $(E \%)$ of $\mathrm{AG}$ film is increased by $6 \%$ when cellulose is loaded and it also shows similar changes as that of TS and YM of the films [36]. It also shows a good elasticity of the films. From the results, it has been concluded that the film made with cellulose and agar (CMF film) shows a good mechanical strength and hence, it can be used as a food-packaging material. The formation of CMF film is shown in figure 4 .

3.4b Water solubility: Table 2 shows the WS\% of agar and agar-based films. The result from the table implies that there is a reduction in WS\% of CMF film to $54 \pm 0.2$ when compared with the other two films. It is because of the formation of a strong hydrogen bond between agar matrix and cellulose where cellulose increases its cohesive property between agar and decreases the solubility of water [37].

3.4c Light transmission and opacity: Light transmission of agar and agar-based nanocomposite films were measured

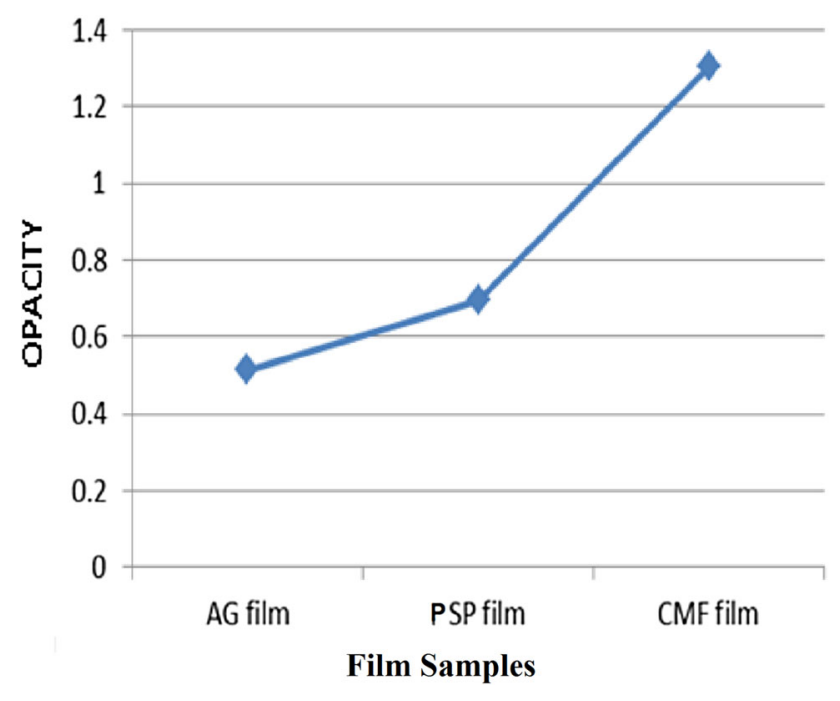

Figure 6. Opacity of the film samples.

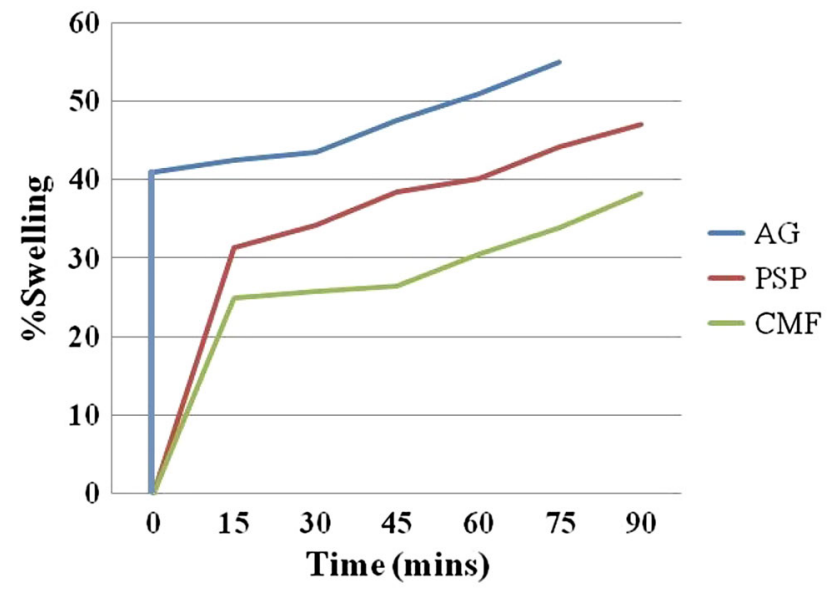

Figure 7. Swelling properties of film samples.

and presented in figure $5 \mathrm{a}-\mathrm{c}$. The result indicates that the transmittance values of agar film are lesser than that of CMF film. With the addition of cellulose onto the agar matrix, light transmission value decreases, which is due to the higher interaction between agar matrix and cellulose. This proves that agar and cellulose bind strongly and can be used as a good food-packaging material [38].

The opacity of the films is shown in table 2 . The results indicate that the opacity value of CMF and PSP films was increased when compared with agar films. This is due to the formation of strong agglomeration between agar and cellulose $[35,39]$. Figure 6 shows the graphical representation of opacity of the film samples.

3.4d Swelling properties: Swelling properties of the films were measured and represented in figure 7 . From the figure, it shows that CMF film shows lesser swelling properties when compared to AG film. It is because when cellulose binds 
Table 3. Biodegradability of film samples.

\begin{tabular}{lcccccccccc}
\hline & \multicolumn{10}{c}{ Days } \\
\cline { 2 - 10 } Samples & 0 & 5 & 10 & 15 & 20 & 25 & 30 & 35 & 40 \\
\hline AG film & $1.2 \mathrm{~g}$ & $1.19 \mathrm{~g}$ & $1.17 \mathrm{~g}$ & $1.16 \mathrm{~g}$ & $1.14 \mathrm{~g}$ & $1.12 \mathrm{~g}$ & $1.10 \mathrm{~g}$ & $1.08 \mathrm{~g}$ & $1.05 \mathrm{~g}$ \\
PSP film & $1.2 \mathrm{~g}$ & $1.18 \mathrm{~g}$ & $1.16 \mathrm{~g}$ & $1.13 \mathrm{~g}$ & $1.09 \mathrm{~g}$ & $1.07 \mathrm{~g}$ & $1.06 \mathrm{~g}$ & $1.03 \mathrm{~g}$ & $1.01 \mathrm{~g}$ \\
CMF film & $1.2 \mathrm{~g}$ & $1.17 \mathrm{~g}$ & $1.14 \mathrm{~g}$ & $1.11 \mathrm{~g}$ & $1.07 \mathrm{~g}$ & $1.04 \mathrm{~g}$ & $1.01 \mathrm{~g}$ & $0.92 \mathrm{~g}$ & $0.86 \mathrm{~g}$ \\
\hline
\end{tabular}

with agar, it forms a stronger interaction between them and it reduces the swelling values, whereas other two films have increased swelling ratios [40-42].

3.4e Soil burial degradation: The results as shown in table 3 indicate that there is an increase in weight loss of the film when cellulose is added to agar matrix. AG films show (11\%) lesser weight loss when compared to CMF film and it is more when compared with PSP film (14.4\%). On comparison with CMF film (26.4\% of weight loss), PSP film shows lesser weight loss because of the presence of lignin in the soil burial degradation test [43]. Thus, the results imply that CMF film not only had a good physical and mechanical properties, but also has an increased biodegradability.

\section{Conclusion}

In this work, CMFs were isolated by a novel laccase treatment for oxidation of lignin and its removal, followed by usual chemical treatment for the removal of lignin, hemicellulose and other extractives. FESEM confirms the morphological structure of cellulose nanofibres indicating the rough surface after the removal of non-cellulosic materials. FTIR measurement reveals the successive removal of lignin and hemicellulose by laccase and chemical treatment and indicates the presence of cellulose. Results from XRD analysis describe the CrI and crystalline size of PSP and CMF samples. Physical and mechanical properties of bio-nanocomposite films imply that CMF film shows a good characteristic property on comparison with other two films. Due to its beneficial effects, CMF films can be used as an alternative for petroleum products, as a natural filler, usage of agro waste into a valuable product and can be applied in various applications, such as food packaging, tissue engineering and so on. This novel technique of cellulose fibre isolation and preparation of bionanocomposite films will motivate future researchers to work on other natural cellulose sources.

\section{References}

[1] Kanmani P and Rhim J W 2014 Carbohydr. Polym. 102708

[2] Tang X Z, Kumar P, Alavi S and Sandeep K P 2012 Crit. Rev. Food Sci. Nutr. 525
[3] Faruk O, Bledzki A K, Fink H P and Sain M 2012 Prog. Polym. Sci. 371552

[4] John M J and Thomas S 2008 Carbohydr. Polym. 71343

[5] Sorrentino A, Gorrasi G and Vittoria V 2007 Trends Food Sci. Technol. 1884

[6] Komolwanich T, Tatijarern P, Prasertwasu S, Khumsupan D, Chaisuwan T, Luengnaruemitchai A et al 2014 Cellulose 21 1327

[7] Reddy J P and Rhim J W 2014 Carbohydr. Polym. 110 480

[8] Alemdar A and Sain M 2008 Bioresour. Technol. 991664

[9] Gonzalez Y M, Camy S and Condoret J S 2012 Int. J. Sust. Eng. 547

[10] Hubbe M A, Rojas O J, Lucia L A and Sain M 2008 Bioresource 3929

[11] Henriksson M, Henriksson G, Berglund L A and Lidstrom T 2007 Eur. Polym. J. 433434

[12] Mussatto S I and Teixeira J A 2010 Current research, technology and education topics in applied microbiology and microbial biotechnology (Spain: Formatex Research Center)

[13] Raju G U, Kumarappa S and Gaitonde V N 2012 J. Mater. Environ. Sci. 3907

[14] Atef M, Rezaei M and Behrooz R 2014 Int. J. Biol. Macromol. 70537

[15] Fazli F A, Ehsani M R, Ghanbarzadeh B and Asadi G H 2012 2nd International Conference on Environmental Science and Biotechnology IPCBEE, Singapore 4825

[16] Azeredo Henriette de M C 2009 Food Res. Int. 421240

[17] Jaiswal N, Pandey V P and Dwivedi U N 2015 Int. J. Biol. Macromol. 72326

[18] Bourbonnais R, Leech D and Paice M G 1998 Biochim. Biophys. Acta 1379381

[19] Majcherczyk A, Johannes C and Hüttermann A 1998 Enzyme Microb. Technol. 22335

[20] Chen W S, Yu H P, Liu Y X, Chen P, Zhang M X and Hai Y F 2011 Carbohydr. Polym. 831804

[21] Haciu D, Saner S, Türdoğru O and Ünal U 2013 Front. Sci. 3 96

[22] Gumuskaya E, Usta M and Kirci H 2003 Polym. Degrad. Stab. 81559

[23] Oun A A and Rhim J W 2016 Carbohydr. Polym. 150187

[24] Tunc S, Angellier H, Cahyana Y, Chalier P, Gontard N and Gastaldi E 2007 J. Membr. Sci. 289159

[25] Alboofetileh M, Rezaei M, Hosseini H and Abdollahi M 2013 J. Food Eng. 11726

[26] Lavorgna M, Piscitelli F, Mangiacapra P and Buonocore G G 2010 Carbohydr. Polym. 82291

[27] Laxmeshwar S S, Madhu Kumar D J, Viveka S and Nagaraja G K 2012 Der Pharma Chemica 4159 
[28] Zhang L, Ruan D and Zhou J P 2001 Ind. Eng. Chem. Res. 40 5923

[29] Sun R C, Tomkinson J, Wang Y X and Xiao B 1998 Polymer 41 2647

[30] Wada M, Heux L and Sugiyama J 2004 Biomacromolecules 5 1385

[31] Segal L, Creely J J, Martin A E and Conrad C M 1959 Text. Res. J. 29786

[32] Zaini L H, Jonoobi M, Tahir P and Karimi S 2013 Sci. Res. 4 37

[33] Das K, Ray D, Bandyopadhyay N R, Ghosh T, Mohanty A K and Misra M 2009 Cellulose 16783

[34] Agustin M B, Ahmmad B, Richel E P, Leon D, Buenaobra J L, Salazar J R et al 2013 Polym. Compos. 341325

[35] Liu D, Zhong T, Chang P R, Li K and Wu Q 2010 Bioresour. Technol. 1012529
[36] Missoum K, Belgacem M N and Bras J 2013 Materials 6 1745

[37] Abdollahi M, Rezaei M and Farzi A G 2012 J. Food Eng. 111 343

[38] Sainz C B, Bras J, Williams T, Sénechal T and Orts W 2011 Carbohydr. Polym. 861549

[39] Pereda M, Amica G, Rácz I and Marcovich N E 2011 J. Food Eng. 10376

[40] Atef M, Rezaei M and Behrooz R 2014 Int. J. Biol. Macromol. 70537

[41] Cao X, Chen Y, Chang P R, Muir A D and Falk G 2008 Express Polym. Lett. 2502

[42] Huq T, Salmieri S, Khan A, Khan R A, Le Tien C, Riedl B et al 2012 Carbohydr. Polym. 901757

[43] Sarsari N A, Pourmousa S and Tajdini A 2016 Bioresource 11 6968 